Relations industrielles

Industrial Relations

\title{
Statistiques de la Province de Québec, Ministère de l'Industrie et du Commerce, Division des études spéciales, Bureau de la Statistique du Québec, vol. I, no 6, sept. 1962.
}

\section{Louis-Marie Tremblay}

Volume 17, numéro 4, octobre 1962

URI : https://id.erudit.org/iderudit/1021491ar

DOI : https://doi.org/10.7202/1021491ar

Aller au sommaire du numéro

Éditeur(s)

Département des relations industrielles de l’Université Laval

ISSN

0034-379X (imprimé)

1703-8138 (numérique)

Découvrir la revue

Citer ce compte rendu

Tremblay, L.-M. (1962). Compte rendu de [Statistiques de la Province de Québec, Ministère de l'Industrie et du Commerce, Division des études spéciales, Bureau de la Statistique du Québec, vol. I, no 6, sept. 1962.] Relations industrielles / Industrial Relations, 17(4), 505-505. https://doi.org/10.7202/1021491ar

Tous droits réservés @ C Département des relations industrielles de l’Université Laval, 1963
Ce document est protégé par la loi sur le droit d'auteur. L'utilisation des services d'Érudit (y compris la reproduction) est assujettie à sa politique d'utilisation que vous pouvez consulter en ligne.

https://apropos.erudit.org/fr/usagers/politique-dutilisation/ 
sition diamétralement opposée et que les Etats-Unis ont cherché à concilier les humanités, les sciences et l'organisation. Il constate aussi une énorme confusion dans la présentation des statistiques parce que les divers pays n'ont pas un dénominateur commun pour définir ce qu'est l'enseignement supérieur, etc. Il critique vertement la pratique de certains pays qui pour des motifs de prestige national ou de propagande politique faussent les statistiques éducatives.

L'auteur dénote une grande érudition ainsi qu'une connaissance théorique et factuelle très poussée du problème de l'éducation. Son analyse s'appuie sur une documentation considérable et très diversifiée qu'il décortique avec perspicacité et sagacité en soulignant les erreurs auxquelles il apporte les corrections appropriées.

Sans être spécialiste des questions de l'éducation, nous sommes persuadés que les personnes dont c'est la sphère d'activité apprécieront beaucoup «Sociologie de l'éducation » non seulement à cause de l'ampleur de sa documentation, mais aussi, à cause des problèmes qu'il découvre et du défi qu'il lance à nos civilisations modernes.

\section{L.-M. Tremblay}

\section{Statistiques de la Province de Québec,} Ministère de l'Industrie et du Commerce, Division des études spéciales, Bureau de la Statistique du Québec, vol. I, no 6, sept. 1962.

Il y a quelques mois, le Bureau de la Statistique du Québec, lançait une nouvelle revue consacrée à la présentation unifiée des principales statistiques sur la province de Québec. Le contenu du sixième numéro, paru en septembre 1962, indique que cette revue a adopté sa forme définitive après avoir, à l'occasion du premier numéro, fait appel aux suggestions et aux critiques des lecteurs. Le temps est donc venu d'en faire une brève appréciation.

On ne saurait, en premier lieu, trop féliciter et encourager les responsables de cette heureuse initiative; l'honorable André Rousseau et monsieur René Tremblay respectivement ministre et sous-ministre au ministère du Commer$\mathrm{ce}$ et de l'Industric. Bien que ne contenant pas d'informations inédites, cette revue constitue un excellent instrument de travail qui répond à un besoin, parce qu'elle réunit dans une même publication les données essentielles sur la province.

Le dernier numéro contient un intéressant éditorial sur la situation conjoncturelle de la province de Québec. Nous souhaitons que cette pratique diun article de fond se continue et même que l'on y accorde encore plus d'espace.

L'information statistique se divise en quatre parties. La première couvre les principaux indicateurs économiques. La seconde touche le monde du travail : emploi, salaires, revenus, chômage ainsi que les grèves et lock-out. Personnellement, nous accepterions plus d'informations syndicales, telles que le nombre et la répartition des effectifs syndicaux. La troisième traite des prix, de la production industrielle et manufacturière ainsi que de la construction. La dernière, plus diversifiée, porte sur l'agriculture et Palimentation, le commerce, le transport et la finance.

Comme nous l'avons dit précédem. ment, cette revue ne tire pas son originalité des informations qu'elle contient. La plupart des statistiques sont empruntées au B.F.S. : comptes nationaux, revue statistique du Canada, emploi et salaires, rapport statistique sur l'application de la loi sur l'assurance-chômage, prix et indices des prix, etc. Le reste se retrouve dans les diverses publications du Bureau de la Statistique du Québec. L'originalité provient plutôt de la réunification des diverses données, de leur présentation comparative avec l'Ontario et le Canada ainsi que des divers graphiques qui permettent en un coup d'oeil d'avoir une idée claire et rapide de la situation dans chaque cas.

Nous sommes persuadés que ceux qui sont appelés à recourir à ce genre d'informations statistiques, $y$ trouveront un bon instrument de travail, qui favorise la confrontation rapide de données diverses.

\section{L.-M. Tremblay}

La situation syndicale dans la Fédération de Malaisie. Rapport d'une mission du Bureau international du travail. Bureau international du travail, Genève, 1962. 120 pages.

Dans le cadre des enquêtes sur la pratique de la liberté syndicale entre- 